\title{
URGENSI MEMBACA DENGAN IQ, EQ DAN SQ UNTUK PEMBANGUNAN MANUSIA DALAM PENDIDIKAN ISLAM
}

\author{
Oleh: Rohmat
}

\section{Abstract}

The article elaborates the urgent of reading as one of methods for human development in Islamic Education. Reading is the first revelation received by Rasulullah. Therefore, it is a crucial aspect in the process of human empowerment. However, the problem is that reading activities are still assumed as brain activities which are a part of Intelligence Quotient/IQ. In fact, reading can really empower human being if it is involving Emotional Quotient/EQ, and Spiritual Quotient/SQ.

The article provides a conclusion that human empowerment requires reading process that engages Intelligence Quotient/IQ, Emotional Quotient/EQ, and Spiritual Quotient/SQ.

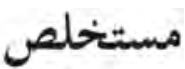

لقد كان الأمر بالقراءة أول أمر إلمي تلقاه النبي محمد (ص)؛ من أجل هذا، يككن النظر للقراءة كأحد العناصر الأهم في عملية تمكين الإنسان في منظومة التربية الإسلامية. تطرح

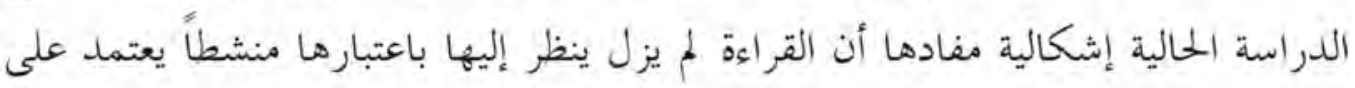

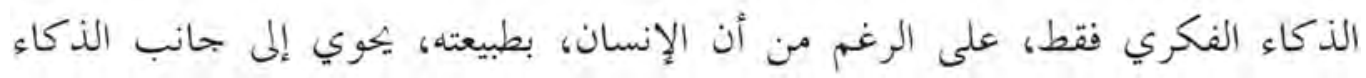

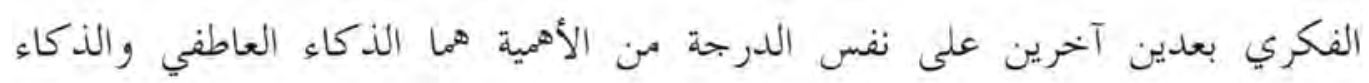
الروحي. من أجل هذا، تطرح الدراسة رؤية منهجية لتعليم القراءة عبر استخدام الأبعاد الثلاثة 


\section{المذكورة بشكل متكامل، من أجل تمكين الإنسان من تحقيق قدراته ومواهبه الذاتية في ظل منظومة التربية الإسلامية بشكل أكبر.}

Keywords: Membaca, Pembangunan Manusia, IQ, EQ, dan SQ

\section{A. Pendahuluan}

Pertumbuhan dan perkembangan manusia ditandai dengan berbagai produk kemajuan. Kemajuan dalam Intelligence Quotient (IQ), Emotional Quotient (EQ) dan akhir-akhir ini adalah Spiritual Quotient (SQ). Semuanya merupakan suatu realitas dari aktivitas kehidupan. IQ, EQ, dan SQ dalam pengkajiannya sebagai perfektif humanis. Hal ini merupakan sebuah kenyataan yang melekat pada manusia yang dibangun seumur hidup. Karena itu, kebutuhan membaca merupakan awal memperoleh pengetahuan.

Islam menjelaskan manusia agar membaca sebagaimana yang diperintahkan kepada Muhammad saw. Membaca sebagai bagian kegiatan yang melibatkan IQ, diekpresikan dalam IQ dan bertumpu dalam transcendental intelegence dari lahir sampai mati. Obsesi membaca adalah aktifitas belajar yang tidak terikat waktu dan ruang terhadap apa saja harus dapat ditangkap sebagai proses belajar. Karena membaca bukan hanya bertujuan bebas buta huruf akan tetapi menyerap substansi kehidupan sesuai perkembangan zamannya. Titik fokus pendidikan Islam tidak terbatas pada kemampuan beribadah, membaca Al-Qur'an, shalat dan sebagainya sebagaimana asumsi sebagian orang, tetapi mencakup seluruh aspek kehidupan. ${ }^{1}$

Persoalannya, untuk membangun manusia Indonesia sepanjang masa tidak bertumpu kepada IQ saja. Bila ini terjadi yang berkembang pengetahuan dalam otak yang akhirnya dapat mendewakan kemampuan materi sehingga menjadi materialistis dan mengarah pada dunia imperalistis bahkan bisa terpikat pada ateisme. Untuk itu, membangun manusia Indonesia perlu dikembangkan dengan SQ. Adapun EQ menjadi prasyarat dasar penggunaan IQ. ${ }^{2}$

Selain itu, gambaran totalitas kecerdasan manusia dapat dilengkapi dengan perbincangan tentang SQ. SQ memberi peluang besar untuk menghadapi dan

1 Ruswan Thoyib dan Darmu'in, Pemikiran Pendidikan Islam, (Yogyakarta: Fakultas Tarbiyah IAIN Walisanga Semarang bekerjasama dengan Pustaka Pelajar Yogyakarta, 1999), hal. 49.

2 Donah Yohar dan Ian Marshall, SQ Memanfaatkan Kecerdasan Spiritual dalam Berpikir Integralistik dan Holistik untuk Mamaknai Kehidupan, (Bandung: Mizan, 2001), hal. 3. 
memecahkan persoalan makna dan nilai, yaitu kecerdasan menempatkan perilaku dan hidup manusia dalam konteks makna yang lebih luas. Kecerdasan untuk menilai tindakan atas hidup seseorang lebih bermakna dibandingkan dengan yang lain. SQ adalah landasan yang diperlukan untuk memfungsikan IQ dan EQ secara efektif.

${ }^{3}$ Karena itulah, kajian ini hendak mengungkap pentingnya membaca dengan IQ, EQ, dan SQ untuk pembangunan manusia sepanjang masa dalam pendidikan Islam.

\section{B. Analisis Awal}

\section{Kecerdasan Intelektual}

Kecerdasan intelektual atau yang biasa disebut Intelligence Quotient (IQ) merupakan persyaratan minimum kompetensi. IQ dapat dikembangkan optimal dengan memahami sistem kerja otak manusia dalam beraktivitas.

Penelitian mutakhir menunjukkan bahwa otak manusia terdiri dari bermiliar-miliar sel aktif. Ada minimal terdiri 100 miliar sel otak aktif sejak lahir. Setiap sel dapat membuat jaringan sampai 20.000 sambungan setiap detik. Otak manusia berkembang melalui proses belajar-alamiah dengan kecepatan 3 miliar sambungan per detik. Sambungan-sambungan ini adalah kunci kekuatan otak. Hal yang sangat menakjubkan otak terdiri dari beragam hal: bagian, fungsi, kemampuan, dan lain-lain. ${ }^{4}$

Otak kiri dan kanan digunakan secara harmonis sehingga manusia dapat menyelesaikan tugas dengan baik dan cepat. Otak kiri berpikir dengan cara urut, bagian per bagian, dan logis. Otak kanan melengkapinya dengan cara berpikir acak, holistik, dan kreatif. Otak kanan sangat membantu dalam proses menghafal cepat, membaca cepat, dan berpikir kreatif.

Dengan demikian, kecerdasan intelektual manusia sangat efektif memperhatikan keseimbangan belahan otak kiri dan kanan dalam kegiatan yang tidak terikat oleh ruang dan waktu sepanjang hidup. Ini perlu disyukuri tidak hanya untuk menguasai aspek materi pelajaran hidup tetapi kompetensi dasar memahami seluk beluk seluruh aspek kehidupan manusia. IQ manusia akan dapat melakukan telaah berbagai kompleksitas kehidupan

Ibid, hal. $3-4$.

4 Agus Nggermanto, Quantum Quotient, (Bandung: Yayasan Nuansa Cendekia, 2001), hal. 38. 
dalam belajar sepanjang masa termasuk berbagai variabel konkret dan abstrak. IQ manusia dapat meneropong variabel abstrak seperti persoalan irrasional menjadi logis mengenai surga dan neraga, termasuk materi pendidikan Islam.

\section{Kecerdasan Emotional}

Hubungan antarmanusia perlu dilandasi dengan kecerdasan emosional. Komunikasi berkualitas manusia akan mampu saling berhubungan dengan harmonis. Bila dicermati, pendidikan di Indonesia terkesan menekankan pada nilai akademik, bertumpu kecerdasan otak. Pendidikan tentang kecerdasan emosi atau Emotional Quotient (EQ) yang mengajarkan kejujuran, komitmen, ketahanan mental, keadilan, kebijaksanaan, integritas, kreativitas, penguasaan diri, kepribadian luhur jarang menjadi fokus untuk dilakukan. Padahal, inilah yang urgen.

Dalam pendidikan Islam akhlak adalah utama. Akhlak mampu menjaga keharmonisan sesama manusia. Keharmonisan hubungan sesama manusia perlu didasari dengan kecerdasan emosional. Kecerdasan emosional sama pentingnya dengan kecerdasan intelektual. EQ memberi kesadaran mengenai perasaan diri sendiri dan perasaan orang lain. EQ memberi rasa empati, cinta, motivasi, dan kemampuan untuk menanggapi kesedihan atau kegembiraan secara tepat. ${ }^{5}$

\section{Kecerdasan Spiritual}

Kecerdasan spiritual atau Spiritual Quotient (SQ) menuntun moralitas manusia, kemampuan menyesuaikan aturan, serta membedakan baik dan buruk. SQ mengintegrasikan semua kecerdasan manusia. SQ menjadikan manusia makhluk yang totalitas. SQ memelihara manusia menjadi makhluk paripurna, yakni sungguh utuh secara kecerdasan, emosional, dan spiritual.

Idealnya, ketiga kecerdasan dasar manusia bekerjasama saling mendukung. Otak manusia dirancang agar mampu melakukannya. Sekalipun demikian, IQ, EQ, dan SQ memiliki wilayah kekuatan tersendiri dan bisa berfungsi secara terpisah. Oleh karena itu, ketiga kecerdasan manusia belum tentu sama-sama tinggi atau rendah. Seseorang tidak harus tinggi dalam IQ atau SQ agar tinggi dalam EQ karena seseorang mungkin tinggi IQ-nya tetapi rendah EQ dan SQ-nya. ${ }^{6}$

5 Donah Yohar dan Ian Marshall, SQ Memanfaatkan Kecerdasan Spiritual..., hal. 3.

6 Ibid, hal. 5. 
Dengan demikian, dapat disebut bahwa bila IQ, EQ, dan SQ dapat ditumbuhkembangkan dalam perilaku manusia, maka pembangunan manusia sepanjang masa melalui proses pendidikan Islam akan membuahkan keharmonisan dalam kehidupan.

\section{Urgensi Membaca dengan IQ, EQ, dan SQ}

Islam memerintahkan manusia agar membaca sebagaimana yang diserukan Allah kepada Nabi Muhammad saw. Membaca bukan hanya melakukan sensori visual dengan penyerapan intelegensia. Membaca perlu dilakukan juga dengan kesadaran emosi. Selain itu, membaca menuntut kecermatan terhadap yang dibaca serta perenungan bahwa pada hakikatnya dengan membaca bisa mengenali keagungan Sang Pencipta. ${ }^{7}$

Jelaslah, keterlibatan secara massif IQ, EQ, dan SQ penting dilakukan ketika membaca. Setidaknya bisa diamati dari beberapa faktor. Pertama, dengan keterlibatan IQ, EQ, dan SQ sekaligus bisa menebalkan keyakinan monoteistik bahwa Allah-lah yang menggerakkan proses membaca. Kedua, iktikad membaca bukan muncul dengan sendirinya, melainkan karena ada kekuatan yang maha dahsyat dari Allah. Ketiga, manusia memiliki keterbatasan dalam hal membaca, sehingga perlu tuntunan dari Allah.

Membaca sebagai bagian kegiatan yang melibatkan IQ, diekspresikan dalam IQ, dengan kesadaran EQ dan bertumpu kepada SQ dari lahir sampai mati. Untuk itu, membaca bukan sekadar kegiatan fisik, melainkan juga kegiatan ruhani.

\section{Hakikat Pembangunan Manusia}

Kesadaran ruhaniah yang paling mendalam adalah kesadaran bahwa hidup itu kesementaraan yang harus dilaksanakan dengan penuh tanggung jawab. Hidup adalah perjalanan singkat menempuh perjalanan panjang dan abadi. Untuk itulah diperlukan bekal. Di sinilah pentingnya pembangunan manusia yang dimulai dengan membaca secara intensif tanpa mengenal sekat ruang dan waktu.

Manusia pada hakikatnya adalah makhluk yang terus berproses dalam belajar. Selama hayat masih dikandung badan, perintah belajar selalu relevan. Dengan kata lain, belajar sejak dalam kandungan hingga liang lahat. Dalam

7 Lihat Q.S. al-'Alaq [96]: 1 - 5. 
konteks demikian, membaca lantas mengalami perluasan makna. Membaca bukan sekadar terhadap lembaran kertas buku, akan tetapi seluruh realitas kehidupan. Pada fase ini terjadi proses komunikasi yang sinergis antara manusia dengan segenap fenomena kehidupan.

\section{F. Pembangunan Manusia dalam Perspektif Pendidikan Islam}

Menuntut ilmu wajib hukumnya bagi setiap muslim, baik laki-laki maupun perempuan. M. Athiyah al-Abrasyi mengatakan bahwa tidak ada pembatasan umur untuk mulai belajar. Secara operasional, pihak lain mengungkapkan bahwa anak mulai belajar dengan persediaan yang ada. Islam telah mengisyaratkan bahwa belajar (mencari ilmu) mulai dari buaian sampai liang lahat.

Secara tersirat, ini menunjukkan pentingnya pengembangan manusia melalui pendidikan. Pendidikan Islam bersifat elastis. Pintunya terbuka bagi setiap manusia belajar dan sanggup untuk terus-menerus belajar dan melakukan penelitian tanpa terikat pada umur, waktu, tempat, dan sebagainya.

Tujuan belajar bukanlah mencari rezeki di dunia ini, tetapi untuk sampai pada hakikatnya, yaitu memperkuat akhlak sempurna. Proses ini harus dilakukan sejak usia belia. Kebiasaan berfikir logis dan penanaman perilaku terpuji harus disentuhkan seawal mungkin pada usia anak. Anak merupakan amanah. Jika dibiasakan yang baik dan dididik maka ia akan besar dengan sifat-sifat baik.

\section{Pengembangan Manusia Berkecerdasan Rohaniah}

Pendidikan Islam tidak mengabaikan problem penyiapan manusia untuk mencari kehidupanya dengan jalan mempelajari beberapa bidang pekerjaan seperti industri dan mengadakan latihan-latihan. Secara konkret pandangan Ibnu Sina menegaskan bahwa manusia dipersiapkan untuk berkarya, berpraktik, dan berproduksi. Dengan demikian, manusia dapat bekerja, mendapat rezeki, hidup dengan terhormat dan tetap memelihara segi-segi kerohanian. Lebih jauh menjelaskan tentang pendidikan Islam sebagian besarnya adalah akhlak, tetapi tetap tidak mengabadikan masalah mempersiapkan pengembangan untuk hidup mencari rezeki, dan tidak pula merupakan areal pendidikan jasmani, akal, hati, kemauan, cita-cita, kecakapan tangan, lidah dan kepribadian.

Ayat pertama yang diturunkan di Gua Hira, menegaskan hal ini. Kata iqra' berarti “bacalah". Pemahaman tentang iqra' kata dari qara'a bermakna menghimpun sesuatu sehingga memiliki tujuan melahirkan satu 
dimensi pengertian yang sangat luas. Ia mencakup proses dengan analisis membaca tentang fenomena dan kondisi sekaligus perintah untuk segera mengemban misi menjadikan hidup bermakna. Gerakan memanusiawikan manusia ditandai dengan diturunkan wahyu pertama yang memiliki makna secara luas. Iqra' bukan hanya pesan untuk membaca huruf akan tetapi juga memberikan pencerahan kemampuan manusia membaca situasi yang dimulai dari hati terhadap kehidupan dalam segala aspek dengan menyiapkan diri melalui membaca.

Dalam Surat al-Alaq [96] ayat 1 dijelaskan: Bacalab dengan menyebut nama Tuhanmu yang menciptakan. Dengan demikian, manusia berketetapan bahwa tidak ada makna yang lebih mendalam daripada memperteguh keyakinan, yaitu sebagai makhluk Tuhan Maha Pencipta. Kecerdasan rohaniah yang melekat pada diri manusia akan membimbing manusia belajar hidup bermakna. Tuhan tempat bersandar, nuansa jiwa merasakan keteduhan karena perlindungan Tuhan.

Surat al-Alaq [96] ayat 2-5 menegaskan: Dia menciptakan manusia dari segumpal darah. Bacalah dan Tuhanmulah yang paling pemurah, yang mengajar (manusia) dengan qolam. Dia mengajarkan kepada manusia apa yang tidak diketahuinya. Dari ayat tersebut, manusia dicipta, dikenalkan sifat Tuhan, diajar segala sesuatunya diawali dari perlindungan Tuhan Maha Pencipta. Manusia pada hakikatnya adalah ciptaan yang paling unggul. Maka, manusia hidup tidak lain dipersilakan untuk memilih apa yang menjadi pilihannya. Manusia sebagai wakil Tuhan di bumi (khaliffah fil ardhi) dan sebaik-baik masyarakat (khairu ummah).

Awal ilmu dari komunikasi, komunikasi dapat dimulai dari membaca. Bisa membaca tulisan sesuai muatannya, atau juga perlu peka membaca fenomena yang terjadi dalam kehidupannya. Kemampuan membaca seluruh aspeknya mengantarkan pada pemahaman dan penguasaan ilmu. Dalam mencari kepentingan duniawi ilmu merupakan bagian menuju keunggulan, bahkan penguasaan ilmu pengetahuan bukan saja berperan sebagai instrumen tetapi sekaligus menuju kehidupan yang abadi.

Maka, tepatlah sabda Nabi Muhammad saw. berikut:

Barang siapa yang ingin bahagia di dunia, harus dengan ilmu. Dan barang siapa yang ingin bahagia di akhirat, harus dengan ilmu. Dan barang siapa yang ingin bahagia pada kedua-duanya, juga harus dengan ilmu. 
Pendidikan Islam menempatkan penguasaan ilmu pengetahuan sebagai instrumen untuk meraih keunggulan hidup. Dapat dipahami bahwa tidak memiliki pilihan lain kecuali harus mampu menempatkan pendidikan Islam sebagai wahana untuk mengelola pengembangan manusia termasuk penyiapan pembangunan ekonomi, penguasaan ilmu pengetahuan, dan teknologi

\section{Pengembangan Manusia Ekonomikus}

Setelah isyarat melalui wahyu Illahi di Gua Hira maka belenggu buta baca dan tulis secara perlahan terurai. Semakin hari kualitas pribadi manusia meningkat bahkan peka menangkap fenomena kehidupan. Kompleksitas persaingan pun terjadi terlebih dalam bidang ekonomi. Untuk itu, sesuai perkembangan ilmu pengetahuan dan teknologi maka segenap umat manusia siap mengembangkan dirinya sehingga memiliki kemampuan belajar (learning capability) yang terus terpelihara menghadapi sektor lain, termasuk sektor ekonomi.

Problematika ekonomi seperti perniagaan, produksi, distribusi hingga konsumsi merupakan urusan yang berkaitan dalam kehidupan. Urusan ekonomi ini sebenarnya ada dalam salah satu rukun Islam yakni zakat. Dengan demikian, konsep zakat sebenarnya memiliki dimensi ekonomi yang sangat luas. Jika disimak dari rukun Islam yang pertama, yakni membaca syahadat maka sebenarnya muatan yang diserap sangat luas. Bukan hanya berikrar akan tetapi juga membaca sepenuh hati dengan makna keyakinan yang paripurna, yaitu pengakuan yang totalitas, memasuki dunia ketentraman menuju kepada kedamaian abadi. Suwandi menegaskan bahwa seluruh gerak dan pemikiran yang melingkupi pendidikan bermakna dalam pada dimensi tauhid, baik dimensi metodologi maupun dimensi konstekstual. Secara sederhana pendidikan berwawasan tauhid hendaknya mampu mengintegrasikan ketiga arah yakni kognitif, efektif, dan psikomotor dalam satu paket pendidikan yang integratif. ${ }^{8}$

Rukun Islam yang kedua berupa pelaksanaan atas keyakinan dan pengakuan sehingga tampak dalam ekspresi komunikasi. Komunikasi berlangsung dalam suasana keteduhan, kedamaian, kesungguhan, dan

8 Suwadi, "Pendidikan Islam Berwawasan Tauhid", Jurnal Ilmu Pendidikan Islam, Vol. 2 No. 1, 2001, hal. $24-35$. 
keikhlasan pada waktu tertentu di ruang yang suci dalam perlindungan Allah. Dalam komunikasi dibimbing oleh keyakinan yang mendalam sepenuh hati. Bentuk komunikasi dilakukan dengan suatu cara yang terpola sinergis. Setiap gerakan yang dilakukan memberikan pelajaran bagi manusia.

Hikmah yang tampak jelas di antaranya adalah pentingnya menghargai waktu (disiplin). Manusia hendaknya tanggap, responsif, dan mampu membaca situasi untuk berkarya. Manusia yang mampu membaca peluang sebenarnya mampu belajar. Produktifitas manusia tanpa kehilangan waktu merupakan prinsip dalam wirausaha. Esensi wirausaha mengedepankan pemanfaatan waktu seefisien mungkin dengan produk yang optimal. Dengan demikian, pengembangan manusia ekonomikus dapat dimulai dari membaca peluang dengan pemanfaatan waktu efisien dengan produk yang optimal.

Rukun Islam ketiga adalah puasa. Ini memberikan isyarat terhadap pemahaman pengertian terobosan bagi manusia yang lemah ekonomi. Manusia yang berkecukupan mampu merasakan penderitaan manusia ekonomi lemah. Dengan demikian, akan diperoleh pemahaman membaca aspek kepentingan orang lain, sehingga pemahaman ekonomi dapat dimengerti secara luas.

Sekalipun urusan ekonomi telah jelas dalam rukun Islam mengenai zakat, tetapi menurut hemat penulis perlu kemampuan melakukan ekplorasi menjadikan tiang pancang ekonomi Islam. Zakat bukan ditunjukkan pada manusia tertentu tetapi sebenarnya dijadikan alat untuk mengatasi persoalanpersoalan ekonomi. Tidak sedikit isyarat firman oleh Allah melalui ayat-ayat Al-Qur'an yang dijadikan bahan eksplorasi dalam masalah ekonomi. Misalnya, agar tidak terjadi pemutaran atau peredaran modal hanya dikalangan sekelompok kecil orang. ${ }^{9}$

Dalam konstruksi era industrial, khususnya mengenai pola bagi keuntungan antara majikan/pengusaha dan karyawan perlu didasarkan pada kesadaran pengusaha bahwa dalam aset perusahaan pada hakikatnya memuat kepemilikan para karyawannya. ${ }^{10}$ Dari kesadaran kedua pihak timbullah rasa saling menghargai, memahami, menghormati, dan membutuhkan dengan menjaga etika. Dengan demikian, karyawan dapat duduk sama rendah berdiri sama tinggi sehingga tidak dianggap sebagai alat.

9 Lihat Q.S. al-Hasyr [59]: 7.

10 Lihat Q.S. al-Ma'arij [70]: 24. 


\section{G. Landasan Pembentukan Manusia Paripurna}

Esensi paripurna dapat disederhanakan menjadi fokus perhatian dalam penulisan ini, yaitu mengenai mutu. Pengertian mutu dalam konteks ini mencakup mutu berilmu pengetahuan sehingga memiliki wawasan luas dan terampil. Dalam kaitan ini, Islam mendasari pembentukan manusia paripurna dengan pendidikan. Misalnya, perilaku orang tua (dalam keluarga) ketika anak baru lahir harus diazani dan diqomati. Hal ini memuat berbagai dimensi dalam pengembangan manusia, di antaranya: 1) sentuhan kalimat spiritual memberi isyarat terhadap kekuatan rohani yang berkaitan dengan kaidah dalam pendidikan kaidah; 2) sebagai bekal dalam konteks keimanan; dan 3) memulai kiprahnya sesuai pertumbuhan dan perkembangannya.

\section{H. Landasan Perilaku Kepribadian}

Ajaran Islam penuh dengan nilai moral untuk melandasi perilaku. Inilah intinya. Jika bobrok moralnya maka hancurlah umat Islam. Sebagaimana disitir Ahmmad Syauqi Beq: "Bangsa itu hanya bisa tetap (bertahan) selama mereka memiliki akhlak. Jika akhlak itu lenyap maka lenyap pula kaum itu".

Al-Abasyi menguraikan beberapa konsep tentang pengembangan manusia. Pertama, sebelum belajar anak itu harus terlebih dahulu membersihkan hatinya dari segala sifat buruk, karena belajar dan mengajar itu dianggap sebagai ibadah. Ibadah tidak sah kecuali dengan hati yang suci berhias dengan moral yang baik seperti berkata benar, ikhlas, takwa, rendah hati, zuhud, menerima apa yang ditentukan Tuhan serta menjauhi sifat-sifat buruk seperti dengki, iri, sombong, menipu, tinggi hati, dan angkuh. Kedua, belajar untuk mengisi jiwa bukan untuk berbahagia. Pandangan tersebut tampak konkret bahwa belajar dimulai dari dalam diri anak dalam struktur keluarga melandasi pengembangan manusia dalam pembentukan pribadi yang paripurna. ${ }^{11}$

Muhammad Zein menyatakan bahwa masalah manusia selamanya menghendaki pengertian dan pengembangan terus menerus untuk suatu waktu. ${ }^{12}$ Lebih jauh M. Athiyah al-Abrasyi menegaskan tentang studi atas kemampuankemampuan manusia dan hubungannya dengan pendidikan akhlak serta moral.

11 M. Athiyah Al-Abrasyi, Dasar-Dasar Pokok Pendidikan Islam, Jakarta: Bulan Bintang, 1970), hal. 149-150.

12 Muhammad Zein, Filsafat Pendidikan Islam, (Yogyakarta: Fak. Tarbiyah IAIN Suka, 1985), hal. 4. 
Bahwa dalam diri manusia terdapat: 1) kemampuan untuk membedakan dan memikir; 2) sifat marah, membantu kawan, gila kekuasaan dan penonjolan diri; dan 3) hawa nafsu termasuk kelezatan panca indera.

Maka dari itu, akhlak menjadi jiwa manusia untuk melandasi pada pengembangan kepribadiannya. Harapan agar akhlak bukan menjadi hiasan melainkan juga sebagai moral pertumbuhan dan pengembangan moral manusia. Idealnya, masyarakat madani dapat diwujudkan jika dimulai dengan kemajuan, stabilitas, berdikari, mandiri, demokratis, adil dan kompetitif mengandalkan kualitas pendidikan dalam berbagai jenis keilmuan dan keterampilan. ${ }^{13}$ Hal inilah yang harus lebih awal ditanamkan.

\section{Hubungan IQ, EQ Dan SQ Dengan Pendidikan Berbasis Karakter}

Manusia tidak menjalani satu aspek saja dalam kehidupan, sebab kompleksitas kehidupan dipengaruhi oleh lingkungan. Lingkungan sosial adalah interaksi dari perwujutan IQ, EQ dan SQ. Manusia yang melakukan interaksi bertumpu kepada the basics of living values (BLV). BLV mencakup dasar-dasar nilai kehidupan seperti kebebasan, kejujuran, tanggung jawab, sederhana, perdamaian, toleransi, kepekaan sosial, demokrasi, percaya diri sendiri, gotong royong, disiplin, saling menghormati, dan religi. BLV berapresiasi dalam kehidupan riil yang berkaitan dengan IQ, EQ dan SQ. BLV dan IQ, EQ dan SQ mempunyai hubungan dalam pembentukan karakter manusia. Pendidikan adalah perubahan perilaku. Dalam proses pendidikan maka BLV dan IQ, EQ dan SQ perlu menjadi orientasi. Pendidikan berorientasi karakter menjadikan manusia berbudi mulia.

Dengan demikian, pendidikan berbasis karakter menjadi jiwa dalam pembentukan manusia Indonesia berakhlak luhur yang bermartabat dan mengedepankan pembangunan karakter moralitas (morality characters building). Sejalan dengan penegasan Rohmat bahwa pendidikan nilai merupakan upaya yang dimaksudkan untuk membina hati nurani, tentu diarahkan agar anak didik memiliki kepekaan dan penghayatan nilai-nilai luhur sehingga terbentuk pribadi bermoral yang paripurna. ${ }^{14}$

13 Ismail SM \& Abdul Mukti, Pendidikan Islam Demokratisasi Dan Masyarakat Madani, (Semarang: Pustaka Belajar Offset, 2000), hal. 250.

14 Rohmat, Model Pendidikan Nilai Terintegrasi Pada Mata Pelajaran Di Madrasab Ibtida'iyah (MI) Kabupaten Sukoharjo, (Yogyakarta: Pascasarjana Program Doktor UNY, 2002), hal. 10. 


\section{J. Urgensi Membaca dengan IQ, EQ Dan SQ}

Manusia adalah ciptaan Allah yang paling baik. Ini dipertegas oleh Allah dalam Surat at-Tin [95] ayat 4: Sesungguhnya Kami telah menciptakan manusia dalam bentuk yang sebaik-baiknya. Ahmad Khamis menegaskan bahwa manusia merupakan mkhluk yang teristimewa. Keistimewaan itu dilambangkan dengan penganugerahan akal, bahasa, kebudayaan, dan beretika. Namun demikian, Allah menjadikan manusia berbeda di antara sesama mereka dari segi fisik, mental, rezeki, ilmu, dan sebagainya. ${ }^{15}$ Meski demikian, manusia mempunyai hak dan kewajiban sama. Bahkan, hanya takwa yang membedakan di hadapan Allah. Artinya, untuk menjadi insan takwa diperlukan proses. Hal ini perlu ditempuh dengan memberdayakan manusia melalui pendidikan Islam. Pembangunan manusia dalam pendidikan Islam mendapat tempat yang berderajat tinggi. Allah mengisyaratkan bahwa orang-orang yang beriman dan berilmu pengetahuan akan ditinggikan derajatnya.

Pendidikan Islam tidak dimaksudkan untuk mendapatkan ilmu pengetahuan dan teknologi bagi kepentingan dunia saja. Dalam Islam diajarkan kesetimbangan antara urusan dunia dan akherat. Bahkan, ditegaskan pula agar menjaga diri dan keluarga dari cengkeraman api neraka.Ini bermakna bahwa pendidikan Islam memberi keseimbangan untuk menjaga diri dan keluarga dengan proses pendidikan bagi manusia bukan hanya mengandalkan kemampuan intelegensi (IQ) melainkan juga kesadaran emosi (EQ) dan sentuhan makna spiritual (SQ). Untuk itu, penting membaca dengan IQ, EQ dan SQ berkaitan dan sinergi. Hal demikian, akan memberikan andil tidak kecil dalam pembangunan manusia melalui pendidikan Islam. Pemaknaan dapat dicapai manakala urgensitas membaca dengan IQ, EQ, dan SQ berlangsung sinergi untuk pembangunan manusia dalam pendidikan Islam.

\section{K. Penutup}

Islam menjelaskan manusia agar membaca sebagaimana yang diperintahkan kepada Muhammad saw. Membaca sebagai bagian kegiatan yang melibatkan intelligence quotient (IQ), diekspresikan dalam IQ, dengan kesadaran Emotional Quotient (EQ) dan bertumpu kepada Spiritual Quotient (SQ) dari lahir, sampai

15 Ahmad Khamis, Etika, (Kualalumpur: Kumpulan Budiman SDN BHD, 1999), hal. 7. 
mati. Untuk memiliki pengetahuan paripurna pada setiap manusia, maka pembangunan manusia harus dinilai dari stimulus awal ketika manusia mengenal makna hidup dalam proses kehidupannya dengan membaca secara IQ dan dimanifestasikan EQ serta dalam memetik kedamaian hati (qalbun salim) melalui SQ. Kemampuan menempatkan diri dalam dimensi waktu dan ruang, dilakukan sinergi IQ, EQ dan SQ adalah penting untuk pembangunan manusia sepanjang masa dalam bingkai pendidikan Islam mengantarkan setiap manusia dapat mengembangkan kecerdasan rohaniah.

\section{DAFTAR PUSTAKA}

Al-Abrasyi, M. Athiyah. 1970. Dasar-Dasar Pokok Pendidikan Islam. Jakarta: Bulan Bintang.

Darmu'in, Ruswan Thoyib dan. 1999. Pemikiran Pendidikan Islam. Semarang: Fakultas Tarbiyah IAIN Walisanga Semarang bekerjasama dengan Pustaka Pelajar Yogyakarta.

Fajar, Malik. 1998. Visi Pembaruan Pendidikan Islam. Jakarta: CV. Alva Grafikatama. Khamis, Ahmad. 1999. Etika. Kualalumpur: Kumpulan Budiman SDN BHD.

Kuntoro, Sodiq. 1997. "Pengembangan Masyarakat Belajar dalam Kerangka Pembangunan” dalam Majalah Ilmiah Cakrawala.

Marshall, Donah Yohar dan Ian. 2001. SQ Memanfaatkan Kecerdasan Spiritual dalam Berpikir Integralistik dan Holistik Untuk Mamaknai Kebidupan. Bandung: Mizan.

Mayor, Monte. 19994. Ethics: The Philosophy of Life. Manila: National BookStorie Inc.

Mukti, Ismail SM \& Abdul. 2000. Pendidikan Islam Demokratisasi Dan Masyarakat Madani. Semarang: Pustaka Belajar Offset.

Nggermanto, Agus. 2001. Quantum Quotient. Bandung:Yayasan Nuansa Cendekia.

Rohmat. 2002. Model Pendidikan Nilai Terintegrasi Pada Mata Pelajaran Di Madrasah Ibtida'iyah (MI) Kabupaten Sukoharjo. Yogyakarta: Pascasarjana Program Doktor UNY. 
Suwadi. 2001. "Pendidikan Islam Berwawasan Tauhid". Jurnal Ilmu Pendidikan Islam Vol. 2 No. 1.

Tasmara, Toto. 2001. Kecerdasan Rohaniah. Jakarta: Gema Insani Press.

Zein, Muhammad. 1985. Filsafat Pendidikan Islam.Yogyakarta: Fak. Tarbiyah IAIN Suka. 